\title{
Correction to: Adequate period of surveillance in each stage for curatively resected gastric cancer: analyzing the time and rates of recurrence
}

\author{
Akikazu Yago ${ }^{1}$. Shusuke Haruta ${ }^{1} \cdot$ Masaki Ueno $^{1} \cdot$ Yosuke Hamada $^{1} \cdot$ Yusuke Ogawa $^{1} \cdot$ Yu Ohkura ${ }^{1}$. \\ Masayuki Urabe $^{1} \cdot$ Harushi Udagawa $^{1}$
}

Published online: 4 March 2021

(c) The International Gastric Cancer Association and The Japanese Gastric Cancer Association 2021

\section{Correction to: Gastric Cancer \\ https://doi.org/10.1007/s10120-020-01147-4}

In the original publication of the article, the last three column values of Table 3 were messed up. The correct Table 3 is given in this correction.

The original article has been corrected.

Publisher's Note Springer Nature remains neutral with regard to jurisdictional claims in published maps and institutional affiliations.

The original article can be found online at https://doi.org/10.1007/ s10120-020-01147-4.

Shusuke Haruta

shusuke-haruta@umin.ac.jp

1 Department of Gastroenterological Surgery, Toranomon

Hospital, 2-2-2 Toranomon, Minato-ku, Tokyo 105-8470,

Japan 


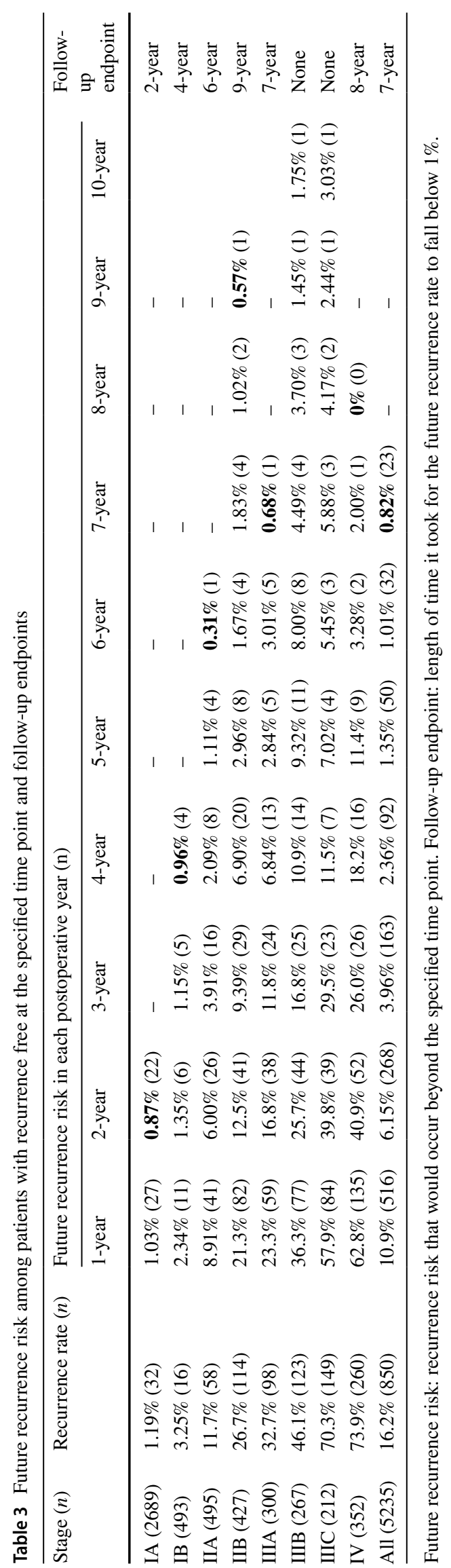

